\title{
A logarithmic rapid desensitization protocol: initial experience in carboplatin hypersensitivity reactions
}

\author{
Enrique Burches ${ }^{1}$, Jose-Alejandro Pérez-Fidalgo² ${ }^{2}$ Francisco Ferriols ${ }^{3}$, Inés González-Barrallo², Andrés \\ Cervantes $^{2}$ \\ 1Allergy Department, Hospital Clinico Universitario, Valencia 46010, Spain. \\ ${ }^{2}$ Oncology Department, Hospital Clinico Universitario and INCLIVA Research Institute, Valencia 46010, Spain. \\ ${ }^{3}$ Pharmacy Department, Hospital Clinico Universitario, Valencia 46010, Spain.
}

Correspondence to: Prof. Enrique Burches, Allergy Department, Hospital Clinico Universitario, Av. Blasco Ibáñez, 17 Valencia 46010, Spain. E-mail: eburchesbaixauli@gmail.com

How to cite this article: Burches E, Pérez-Fidalgo JA, Ferriols F, González-Barrallo I, Cervantes A. A logarithmic rapid desensitization protocol: initial experience in carboplatin hypersensitivity reactions. J Cancer Metastasis Treat 2019;5:63. http://dx.doi.org/10.20517/2394-4722.2019.012

Received: 21 May 2019 First Decision: 21 Aug 2019 Revised: 21 Aug 2019 Accepted: 21 Aug 2019 Published: 28 Aug 2019

Science Editor: Godefridus J. Peters Copy Editor: Jia-Jia Meng Production Editor: Tian Zhang

\begin{abstract}
Aim: Hypersensitivity reactions to carboplatin are not an infrequent adverse event in ovarian cancer patients. However, reintroduction of platinum-containing schedules is the standard of care in platinum-sensitive recurrent ovarian cancer. Rapid desensitization is a procedure for gradual reintroduction of drug. It allows a safe administration of medications that are beneficial for the management of patients after certain types of hypersensitivity reactions. It is indicated in cases in which there are no reasonable therapeutic alternatives.
\end{abstract}

Methods: We performed a descriptive retrospective study of high-grade ovarian cancer patients with known carboplatin hypersensitivity reactions that were treated with a 13-steps rapid desensitization protocol with 3 different solutions and infusion rates. The procedure followed a mathematic model (gradual increases with a relationship between doses following a geometric series) which is called logarithmic rapid desensitization protocol (LRDP). The aim was to describe the safety of the LRDP in terms of number and severity of infusion reactions and the effectiveness in the rate of cycles completely administered.

Results: Four different patients diagnosed with recurrent platinum-sensitive ovarian cancer with a previous infusion reaction were included. LRDP was administered in 19 different cycles. LRDP was administered safety in all 19 cycles, only 2 patients had a mild cutaneous reaction in 4 different cycles during LRDP (21.05\%). The foreseen dose of carboplatin was fully administered in all cycles.

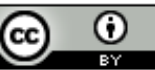

(C) The Author(s) 2019. Open Access This article is licensed under a Creative Commons Attribution 4.0 International License (https://creativecommons.org/licenses/by/4.0/), which permits unrestricted use, sharing, adaptation, distribution and reproduction in any medium or format, for any purpose, even commercially, as long as you give appropriate credit to the original author(s) and the source, provide a link to the Creative Commons license, and indicate if changes were made.

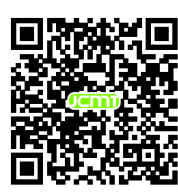


Conclusion: LRDP with carboplatin is a feasible and safe protocol in patients with previous infusion reaction to carboplatin. The protocol might allow a safe administration of drugs, that are beneficial for the management of patients, after certain types of hypersensitivity reactions, and it is indicated in cases in which there are no reasonable therapeutic alternatives.

Keywords: Drug allergy, hypersensitivity, desensitization, rapid protocol, logarithmic model, carboplatin

\section{INTRODUCTION}

Platinum-based chemotherapeutic agents have been used for the treatment of numerous solid tumors affecting several locations (such as breast, ovarian, endometrial, lung, and gastrointestinal tract). As a result of its extended use, platinum compounds have produced an increased number of reactions ${ }^{[1,2]}$. Hypersensitivity reactions are much more frequent with platins than with other drugs. Reactions to carboplatin are a frequent adverse event with an overall incidence of $1 \%-44 \%$ supposing a challenge in the management of ovarian cancer.

In ovarian cancer, platinum-responsiveness have been a classical prognostic factor. Reintroduction of platinum-containing schedules in patients with platinum-responsiveness relapse ( $>6$ months of interval) is widely recommended ${ }^{[3-4]}$. Carboplatin has shown in a randomized trial similar survival than cisplatin but with better safety profile and quality of life ${ }^{[5]}$. Since then carboplatin-containing chemotherapy has been considered standard and, as a consequence, relapsed ovarian cancer patients are frequently exposed to an important number of carboplatin infusions.

Positive carboplatin skin tests and the presentation pattern of these reactions suggest that type I pathway immunological mechanisms are involved. Moreover, platinum-specific IgE can be also found in serum among exposed refinery workers and it supports the theory of type IgE-mediated reaction. Furthermore, clinical symptoms related to a reaction to carboplatin range from a mild rash to severe anaphylaxis; thus, different types of immunologic hypersensitivity seem to be implicated ${ }^{[1]}$.

The fact that the reintroduction of platinum is a major issue in platinum-sensitive patients has prompted the development of desensitization protocols. Rapid desensitization is a procedure for gradual reintroduction of drug at a low dose by dissolving it at a low and intermediate concentration, until reaching the target dose. It allows a safe administration of medications that are beneficial for the management of patients after certain types of hypersensitivity reactions, and it is indicated in cases in which there are no reasonable therapeutic alternatives.

We have performed a retrospective study with the aim of assessing the effectiveness and safety of a logarithm (geometric series) rapid desensitization protocol (LRDP) of carboplatin in patients with platinum-sensitive ovarian relapse that had a previous allergic reaction during carboplatin infusion.

\section{METHODS}

\section{Design}

This is a pivotal study with the objective of assessing effectiveness and safety of LRDP, in terms of number and severity of infusion reactions, in patients with previous reactions to carboplatin exposure and proportion of completely administered carboplatin-containing schedules. A retrospective review of the clinical chart of patients diagnosed with ovarian cancer in our institution since January 2007 was performed. Data extracted from the clinical chart included: (1) diagnosis, pathological variables and demographic data; (2) data from initial infusion reaction; (3) skin tests; and (4) data from the outcome during LPRD and type of reactions occurring during this protocol. 
Classification of the initial reaction bored three aspects: characteristics, severity and timing (time interval between drug administration and the reaction).

Characteristics of clinical symptoms associated with the initial hypersensitivity reactions were categorized by organ system involvement. Cutaneous symptoms (oedema of the face and hands, flushing, pruritus, urticaria or angioedema), respiratory symptoms (dyspnea or wheezing or oxygen desaturation, coughing, nasal congestion), abdominal symptoms (nausea, emesis/vomiting, diarrhea, or abdominal pain), laryngeal angioedema/throat tightness, or cardiovascular symptoms (chest pain, hypotension, hypertension, or tachycardia), neurological/muscular (vision disturbances, weakness, unusual taste, hallucinations, or neurological compromise) according to previous publications ${ }^{[1,2]}$.

Hypersensitivity severity: A mild rash may be the first manifestation of reactions. Hypersensitivity reactions were classified as mild (reactions limited to the skin), moderate (features suggesting respiratory - dyspnea, wheeze -, cardiovascular - dizziness, diaphoresis, chest tightness - or gastrointestinal involvement - nausea, vomiting, abdominal pain -) or severe (hypoxia, hypotension and neurological compromise - confusion, collapse or incontinence -) according to the scale proposed by Brown ${ }^{[6]}$.

As for the timing of reaction, hypersensitivity reactions were categorized as immediate or delayed. Immediate reactions were turned up usually during drug administration while delaying reactions were presented after drug administration.

This retrospective study was approved by the local Ethics Committee of Hospital Clinico Universitario of Valencia (resolution number 320) in November 2016.

\section{Patients}

Patients included had a histological diagnosis of high-grade ovarian carcinoma and a platinum-sensitive relapsed defined as recurrence after at least 6 months of platinum-free interval. Being considered candidates for the LRDP, patients must have presented a hypersensitivity reaction during carboplatin infusion in a previous cycle. Carboplatin hypersensitivity is a late event ${ }^{[7]}$. Consistent with these studies, all reactions in our population occurred after re-exposure to at least seven previous cycles of carboplatin.

In all cases, the initial infusion reaction had been evaluated and managed by emergency staff of the outpatient Oncology department.

Exclusion criteria were an impossibility to understand or to sign informed consent or lack of expected benefit with the reintroduction of carboplatin according to the clinician's opinion.

All patients with a previous type I reaction underwent a skin test with carboplatin before LRDP. Skin testing was performed at least 4 weeks after the initial reaction to minimize the likelihood of false negative results. Drug was diluted further in water with $5 \%$ dextrose for testing. For prick test, a drop of carboplatin $(10 \mathrm{mg} / \mathrm{mL})$ was applied to the volar surface of the forearm followed by pricking. For intradermal injections $0.03 \mathrm{~mL}$ (of a 1:100 dilution followed, if the result was negative, by an 1:10 dilution). A positive reaction was defined as a wheal with a diameter at least $3 \mathrm{~mm}$ large that produced by a negative control. Histamine prick $(10 \mathrm{mg} / \mathrm{mL})$ was used as a positive control ${ }^{[1,2]}$.

Informed consent was obtained from each patient before skin testing and desensitization procedures.

\section{Treatment}

Before (24-72 h previous) administration of LRDP, a blood test including creatinine and hemogram was performed. Patients were then seen in the outpatient unit of Medical Oncology. Treatment was only 
administered if neutrophils count was $\geq 1500$ and platelet count $\geq 100,000$. A total dose of carboplatin was always calculated according to the most recent creatinine levels.

According to the severity of the previous reaction and the results of the skin test, the first cycle of the LRDP was administered under an intensive monitoring in an Intensive Care Unit or under a lighter monitoring surveillance in beds of the Oncology Department inpatient area.

A standard premedication with corticosteroids and antagonists of histamine receptors was administered before desensitization to all patients. Metoclopramide hydrochloryde $10 \mathrm{mg}$ and dexamethasone $8 \mathrm{mg}$ were given intravenously before initiation of LRDP as standard emesis prophylaxis. Histamine blockade $\left(\mathrm{H}_{1} / \mathrm{H}_{2}\right)$ was performed with $5 \mathrm{mg}$ of parenteral dexchlorpheniramine $(5 \mathrm{mg} / \mathrm{mL} \mathrm{amp})$ and ranitidine ( $50 \mathrm{mg}$ i.v.).

The management of reaction during desensitization was intended to block the effects of mast cell mediators, including histamine, prostaglandins and leukotrienes. If symptoms of a hypersensitivity reaction was developed during the desensitization procedure, the infusion was stopped.

In case of a mild reaction, $50 \mathrm{mg}$ of parenteral dexchlorpheniramine $(5 \mathrm{mg} / \mathrm{mL})$ was administered. For severe or recurrent reactions, $40 \mathrm{mg}$ of parenteral methylprednisolone (sodium succinate $0.5 \mathrm{mg} / \mathrm{kg}$ intravenously) and epinephrine $0.3 \mathrm{~mL}(1 \mathrm{mg} / \mathrm{mL})$ were also added. Bronchoespasm and throat tightness was treated with inhaled B-agonists. Flushing was treated with aspirin and montelukast. Once symptoms have resolved, the protocol was resumed and the infusion was restarted at the point where the reaction occurred. All desensitization procedures were prescribed and supervised by the allergy and oncology departments and were conducted under physician supervision.

This 13-step LRDP combined gradual increases in the rate of infusion and concentration of carboplatin, administering the total dose over $5 \mathrm{~h}$ [Table 1].

The total target dose of carboplatin was calculated using the Cockrott-Gault's formulation based on the area under the curve with a creatinine level obtained in no more than $24 \mathrm{~h}$ previous to the LRDP. Three different solutions A, B and C were employed with a total volume of $50 \mathrm{~mL}, 100 \mathrm{~mL}$ and $500 \mathrm{~mL}$ of water with $5 \%$ dextrose respectively and delivered in 13 consecutive steps. The concentrations of the solutions were $0.1 \mathrm{mg} / \mathrm{mL}$ for infusion $\mathrm{A}, 1 \mathrm{mg} / \mathrm{mL}$ for infusion B and $2 \mathrm{mg} / \mathrm{mL}$ for infusion C. Solution A was used for steps 1 to 7 , solution B for steps 8 to 11 and solution C for steps 12 and 13. The total dose of carboplatin administered in the last step was calculated by subtracting the cumulative dose given in the steps 1-12 from the total target dose.

The initial dose was approximately in the order of a $10^{-4}$ times lower (in a rank of $0.2-3 \times 10^{-4}$ ) that the target dose and each step deliver twice the dose of the previous step. All step concentrations are arranged in a geometric series with a factor two. The first term of the series is $1 / 32$ and the common ratio is 2 $(1 / 32,1 / 16,1 / 8,1 / 4,1 / 2,1,2, \ldots \ldots .$.$) . The rate of the infusion was adjusted every 15 \mathrm{~min}$. The final step 13 maintained a constant rate of infusion in order to deliver the remainder of the total carboplatin dose.

\section{RESULTS}

From February 2011 to November 2014, 4 patients with platinum-sensitive recurrence of ovarian cancer that had presented a documented hypersensitivity reaction to the latest carboplatin infusion were treated with LRDP.

Patients characteristics and type of infusion reaction are shown in Table 2. Cutaneous reaction was the most frequent type of reaction to standard carboplatin administration in our series. All patients presented 
Table 1. Logarithmic rapid desensitization protocol

\begin{tabular}{|c|c|c|c|c|c|}
\hline Step & mg & $\mathbf{m L}$ & Flow rate $(\mathrm{mL} / \mathrm{h})$ & Time (min) & Cumulated time \\
\hline \multicolumn{6}{|l|}{ Solution A } \\
\hline 1 & 0.03125 & 0.325 & 1,25 & 15 & $15 \mathrm{~min}$ \\
\hline 2 & 0.0625 & 0.625 & 2.5 & 15 & $30 \mathrm{~min}$ \\
\hline 3 & 0.125 & 1.25 & 5 & 15 & $45 \mathrm{~min}$ \\
\hline 4 & 0.25 & 2.5 & 10 & 15 & $1 \mathrm{~h}$ \\
\hline 5 & 0.5 & 5 & 20 & 15 & $1 \mathrm{~h} 15 \mathrm{~min}$ \\
\hline 6 & 1 & 10 & 40 & 15 & $1 \mathrm{~h} 30 \mathrm{~min}$ \\
\hline 7 & 2 & 20 & 80 & 15 & $1 \mathrm{~h} 45 \mathrm{~min}$ \\
\hline \multicolumn{6}{|l|}{ Cumulated dose $4 \mathrm{mg}$} \\
\hline \multicolumn{6}{|l|}{ Solution B } \\
\hline 8 & 4 & 4 & 16 & 15 & $2 \mathrm{~h}$ \\
\hline 9 & 8 & 8 & 32 & 15 & $2 \mathrm{~h} 15 \mathrm{~min}$ \\
\hline 10 & 16 & 16 & 64 & 15 & $2 \mathrm{~h} 30 \mathrm{~min}$ \\
\hline 11 & 32 & 32 & 128 & 15 & $2 \mathrm{~h} 45 \mathrm{~min}$ \\
\hline \multicolumn{6}{|l|}{ Cumulated dose $60 \mathrm{mg}$} \\
\hline \multicolumn{6}{|l|}{ Solution C } \\
\hline $\begin{array}{l}12 \\
\text { cumulated dose } 128 \mathrm{mg}\end{array}$ & 64 & 32 & 128 & 15 & $3 \mathrm{~h}$ \\
\hline 13 & $\begin{array}{l}\text { Subtraction (final target } \\
\text { dose - total cumulated } \\
\text { dose in steps 1-12) }\end{array}$ & $\begin{array}{l}\text { final target dose - total } \\
\text { cumulated dose)/2 }\end{array}$ & 200 & $2-3 h$ & $5-6 \mathrm{~h}$ \\
\hline
\end{tabular}

Solution A: Concentration $0.1 \mathrm{mg} / \mathrm{mL}$......... $5 \mathrm{mg}$ in $50 \mathrm{~mL}$; solution B: Concentration $1 \mathrm{mg} / \mathrm{mL}$ Concentration $2 \mathrm{mg} / \mathrm{mL}$ $1000 \mathrm{mg}$ in $500 \mathrm{~mL}$

any type of cutaneous reaction. According to severity, the half of patients, 2 out of 4, experienced a mild reaction (either pruritus, urticaria or angioedema).

One patient (1/5) developed a moderate reaction to standard infusion of carboplatin with cutaneous symptoms (palmar rash, pruritus, urticaria), respiratory symptoms (dyspnea) and cardiovascular symptoms (dizziness and diaphoresis).

Another patient (1/5) presented a severe reaction, including cutaneous (edema of the face and handsflushing with palmar erythema, pruritus, urticaria), respiratory (dyspnea and oxygen desaturation) and cardiovascular symptoms (hypotension).

All 4 patients included had developed a reaction to standard carboplatin after at least 7 previous cycles of carboplatin (range 8th-14th cycle of carboplatin).

Regarding skin test results, only one patient had positive skin tests to carboplatin cutaneous exposure at their initial evaluation and the remaining 3 patients were negative. The patient who had specific-IgE (in skin) showed a moderate reaction in relation to the initial reaction and only a cutaneous reaction during the desensitization.

In total, 19 cycles of LRDP carboplatin were administered (in all cases successfully) under the LRDP. The rate of reactions during desensitization procedure was $21.05 \%$ (4 reactions out of 19 cycles), of whom all 4 reactions were considered as mild (palmar and/or facial erythema with pruritus). Despite these reactions, once symptoms have resolved, the foreseen carboplatin dose was fully administered after the protocol was resumed.

\section{DISCUSSION}

This report describes our experience with 19 rapid desensitizations with carboplatin in 4 patients that had a previous hypersensitivity reaction during standard carboplatin infusion. The procedure is successful, and we have been able to complete all the desensitizations undertaken. 
Table 2. Characteristics of patients: type and severity of initial infusion reactions and during LRDP

\begin{tabular}{|c|c|c|c|c|c|c|c|c|c|}
\hline Patient & Type of reaction & Timing & Severity & $\begin{array}{l}\text { Skin } \\
\text { test }\end{array}$ & $\begin{array}{l}\text { Number of cycles } \\
\text { of carboplatin } \\
\text { inducing reaction }\end{array}$ & $\begin{array}{l}\text { Schedule that } \\
\text { induced reaction }\end{array}$ & $\begin{array}{l}\text { Number of } \\
\text { cycles with } \\
\text { LRDP }\end{array}$ & $\begin{array}{l}\text { Schedule } \\
\text { during LRDP }\end{array}$ & $\begin{array}{l}\text { Reaction } \\
\text { during } \\
\text { LRDP }\end{array}$ \\
\hline Patient 1 & Cutaneous & Immediate & Mild & - & $\begin{array}{l}\text { 8th } \\
\text { (2nd line) }\end{array}$ & $\begin{array}{l}\text { Carboplatin } \\
\text { Paclitaxel }\end{array}$ & 6 & $\begin{array}{l}\text { Carboplatin } \\
\text { DLP }\end{array}$ & None \\
\hline Patient 2 & Cutaneous & Immediate & Mild & - & $\begin{array}{l}\text { 9th } \\
\text { (2nd line) }\end{array}$ & $\begin{array}{l}\text { Carboplatin } \\
\text { Gemcitabine }\end{array}$ & 2 & $\begin{array}{l}\text { Carboplatin } \\
\text { Gemcitabine }\end{array}$ & None \\
\hline Patient 2 (II) & & & & & & & 4 & $\begin{array}{l}\text { Carboplatin } \\
\text { DLP }\end{array}$ & None \\
\hline Patient 3 & $\begin{array}{l}\text { Cutaneos } \\
\text { Respiratory } \\
\text { Cardiovascular }\end{array}$ & Immediate & Moderate & + & $\begin{array}{l}\text { 14th } \\
\text { (3th line) }\end{array}$ & $\begin{array}{l}\text { Carboplatin } \\
\text { Gemcitabine }\end{array}$ & 2 & $\begin{array}{l}\text { Carboplatin } \\
\text { Gemcitabine }\end{array}$ & $\begin{array}{l}\text { Cutaneous } \\
(2 / 2)\end{array}$ \\
\hline Patient 4 & $\begin{array}{l}\text { Cutaneous } \\
\text { Respiratory } \\
\text { Cardiovascular }\end{array}$ & Immediate & Severe & - & $\begin{array}{l}\text { 11th } \\
\text { (3th line) }\end{array}$ & $\begin{array}{l}\text { Carboplatin } \\
\text { Gemcitabine } \\
\text { Bevacizumab }\end{array}$ & 5 & $\begin{array}{l}\text { Carboplatin } \\
\text { monotherapy }\end{array}$ & $\begin{array}{l}\text { Cutaneous } \\
(2 / 5)\end{array}$ \\
\hline
\end{tabular}

LRDP: logarithmic rapid desensitization protocol

Carboplatin has had an increasing use and there has been an increase incidence of reactions. When a reaction occurs, options are desensitizing or substituting with a different agent. Successful replacement of carboplatin by cisplatin has been shown in patients with gynecological malignancies ${ }^{[8,9]}$. However, the possibility of developing a reaction to the substituting platinum agent may be as high as $25 \%{ }^{[10]}$ and cases of fatal cisplatin reactions have been reported ${ }^{[11]}$. In this context, substitution of carboplatin must be considered with caution. Because of, desensitization protocols have been successfully used to manage hypersensitivity reactions ${ }^{[1,2,12,13]}$.

Goldberg et al. ${ }^{[14]}$ reported a desensitization regimen in two patients based in serial dilutions, with administration of increasing concentrations of carboplatin. Patients subsequently received infusions of $10^{-3}$, $10^{-2}$, and $10^{-1}$ of the total of the carboplatin dose. The final infusion contained $90 \%$ of the total drug dose.

Castells has developed a successful protocol of desensitization which would be supported by a basic biochemical mechanism: hypo-responsiveness in mast cells associated to suboptimal and increasing doses delivered at fixed time intervals ( $15 \mathrm{~min}$ ). Therefore, specific mast cell and basophils tolerance could be due to the molecular stabilization of membrane, that would permit surpass a threshold antigen concentration required to activate these cells ${ }^{[15]}$. Based on these dates, a 12 -step protocol with a standardized threesolution was generated which allows, for gradual increases in the infusion rate, to administer the target dose over 5-8 h. Doses of antigen must be delivered at fixed time intervals. Steps 1-11 last $15 \mathrm{~min}$, and step 12 was prolonged to complete the target dose. The rate of the infusion was changed every $15 \mathrm{~min}$, which each step delivering approximately twice (2 or 2.5) the dose of the previous step. The final step 12 maintained a constant role of infusion to deliver the remainder of the total dose. According to the description of the own authors, bag A contains a 100-fold lower amount of final target dose diluted in $250 \mathrm{~mL}$ (water with dextrose $5 \%$ ); bag B contains a 10-fold lower amount of final target dose diluted in $250 \mathrm{~mL}$ and bag $\mathrm{C}$ contains final target minus a cumulative dose of previous steps, diluted in $250 \mathrm{~mL}^{[1,2,12,13]}$.

We have chosen a different path to calculate drug concentration of each bag, not giving importance to the concentration of each solution in relation to the target dose as other models. In order to facilitate the calculations, we selected a concentration based on mathematic concepts on the unit. The solution A had a concentration of $10^{-1} \mathrm{mg} / \mathrm{mL}(0.1 \mathrm{mg} / \mathrm{mL})$ of the drug, the solution $B$ had a concentration of $1 \mathrm{mg} / \mathrm{mL}$ and solution C (one only step) was calculated with a concentration of $2 \mathrm{mg} / \mathrm{mL}$ and including the total remaining dose of the drug in order to be administered at a faster speed. The initial dose of protocol had not a direct relationship with the target dose even though was approximately in order of $10^{-4}$ (approximately in a rank of $0.2-3 \times 10^{-4}$ ) lower than the target dose (if this dose is in the rank of 1-1000 $\mathrm{mg}$ ) and this allowed us to apply the protocol in a simpler way. The procedure followed a mathematic model (gradual 
increases with a relationship between doses following a geometric series) which is called LRDP. We have implemented this protocol consisting of 13 doses delivery stages, underlining the accurately relationship between doses in a geometric series. Progression of the doses occurred logarithmically. Each step delivered exactly twice the dose of previous step, in such a way that all step concentrations arranged in a geometric series with a factor two. The first term of the series is $1 / 32$ and the common ratio is $2(1 / 32,1 / 16$, $1 / 8,1 / 4,1 / 2,1,2, \ldots . .$.$) . The total quantity of volume in each of the three bags with each of the solutions is$ not very different from the volume to administer. Therefore, in case of a potential mistake in the schedule, the risk for the patient is minimized.

To enhance patient safety, administration of LRDP was performed by a multidisciplinary team including physicians and nursing staff from the Departments of Allergy, Medical Oncology and Pharmacy. LRDP with carboplatin is a feasible and safe protocol in patients with previous infusion reaction to carboplatin.

In conclusion we have performed a retrospective study with the aim of assessing the effectiveness and safety of a LRDP with carboplatin in patients with a previous reaction. It is a promised protocol for administration of carboplatin after an infusion reaction.

The protocol might allow a safe administration of drugs (it can be applied to other drugs because the therapeutic dose of the majority of drugs is in a range between 1-1000 $\mathrm{mg}$ ), that are beneficial for the management of patients, after certain types of hypersensitivity reactions, and it is indicated in cases in which there are no reasonable therapeutic alternatives.

\section{DECLARATIONS}

\section{Authors' contributions}

Designed the study and wrote the manuscript: Burches E, Pérez-Fidalgo JA

Contributed to data collection: Ferriols F, González-Barrallo I, Cervantes A

\section{Availability of data and materials}

Date are available in data base/Clinical Data Repository of Hospital Clinico de Valencia.

\section{Financial support and sponsorship}

None.

\section{Conflicts of interest}

All authors declared that there are no conflicts of interest.

\section{Ethics approval and consent to participate}

This retrospective study was approved by the local Ethics Committee of Hospital Clinico Universitario of Valencia (resolution number 320) in November 2016.

\section{Consent for publication}

Not applicable.

\section{Copyright}

(c) The Author(s) 2019.

\section{REFERENCES}

1. Patil SU, Long AA, Ling M, Wilson MT, Hesterberg P, et al. A protocol for risk stratification of patients with carboplatin-induced hypersensitivity reactions. J Allergy Clin Immunol 2011;129:443-7. 
2. Hesterberg P, Banerji A, Oren E, Penson RT, Krasner CN, et al. Risk stratification for desensitization of patients with carboplatin hypersensitivity: clinical presentation and management. J Allergy Clin Immunol 2009;123:1262-7.

3. Pujade-Lauraine E. How to approach patients in relapse.Ann Oncol 2012;23:x128-31.

4. Leddermann JA, Raja FA, Fotopoulou C, Gonzalez-Martin A, Colombo N, et al. Newly diagnosed and relapsed epithelial ovarian carcinoma: ESMO Clinical Practice Guidelines for diagnosis treatment and follow-up. Ann Oncol 2013;24:vi24-32.

5. Du Bois A, Luck H-J, Meier W, Adams H-P, Mobus V, et al. A randomized clinical trial of cisplatin/paclitaxel versus carboplatin/paclitaxel as first-line treatment of ovarian cancer. J Nat Cancer Inst 2003;95:1320-30.

6. Brown SG. Clinical features and severity grading of anaphylaxis. J Allergy Clin Immunol 2004;114:371-6.

7. Makrilia N, Syrigou E, Kaklamanos I, Manolopoulos L, Wasif Saif W. Hypersensitivity reactions associated with platinum antineoplastic agents: a systematic review. Met Based Drugs 2010; 2010:207084.

8. Jones R, Ryan M, Friedlander M. Carboplatin hypersensitivity reactions: retreatment with cisplatin desensitization. Gynecol Oncol 2003;89:112-5.

9. Kandel MJ, Loehr A, Harter P, Traut A, Ganuert K, et al. Cisplatinum rechallenge in relapsed ovarian cancer patients with platinum reinduction therapy and carboplatin hypersensitivity. Int J Gynecol Cancer 2005;15:780-4.

10. Ottaiano A, Tambaro R, Greggi S, Prato R, Di Maio M, et al. Safety of cisplatin after sever hypersensitivity reactions to carboplatin in patients with recurrent ovarian carcinoma. Anticancer Res 2003;23:3465-8.

11. Dizon DS, Sabbatini PJ, Aghajanian C, Hensley ML, Spriggs DR. Analysis of patients with epithelial ovarian cancer or fallopain tube carcinoma retreated with cisplatin after the development of a carboplatin allergy. Gynecol Oncol 2002;84:378-82.

12. Castells MC, Tennant TN, Sloane DE, Ida Hsu F, Barret NA, et al. Hypersensitvity reactions to chemotherapy: outcomes and safety or rapid desensitization in 413 cases. J Allergy Clin Immunol 2008;122:574-80.

13. Castells M. Rapid desensitization for hypersensitivity reactions to medications. Immunol Allergy Clin 2009;29:585-606.

14. Goldberg A, Confino-Cohen R, Fishman A, Beyth Y, Altaras M, et al. A modified prolonged desensitization protocol in carboplatin allergy. J Allergy Clin Immunol 1996;98:841-843.

15. Morales AR, Shah N, Castells M. Antigen-IgE desensitization in signal transducer and activator of tra nscription 6-deficient-mast cells by suboptimal doses of antigen. Ann Allergy Asthma Immunol 2005;94:575-80. 